\title{
Targeted Proteomics Comes to the Benchside and the Bedside: Is it Ready for Us?
}

\author{
Anjali Arora and Kumaravel Somasundaram*
}

While mass spectrometry (MS)-based quantification of small molecules has been successfully used for decades, targeted MS has only recently been used by the proteomics community to investigate clinical questions such as biomarker verification and validation. Targeted MS holds the promise of a paradigm shift in the quantitative determination of proteins. Nevertheless, targeted quantitative proteomics requires improvisation in making sample processing, instruments, and data analysis more accessible. In the backdrop of the genomic era reaching its zenith, certain questions arise: is the proteomic era about to come? If we are at the beginning of a new future for protein quantification, are we prepared to incorporate targeted proteomics at the benchside for basic research and at the bedside for the good of patients? Here, an overview of the knowledge required to perform targeted proteomics as well as its applications is provided. A special emphasis is placed on upcoming areas such as peptidomics, proteoform research, and mass spectrometry imaging, where the utilization of targeted proteomics is expected to bring forth new avenues. The limitations associated with the acceptance of this technique for mainstream usage are also highlighted. Also see the video abstract here https://youtu.be/mieB47B8gZw.

\section{Introduction}

The growth of the proteomics field over the last decade has been phenomenal. While antibody-based approaches have played an important role in the advancement of proteomics, the technique of mass spectrometry (MS) is responsible for the extraordinary progress the field has seen. ${ }^{[1]}$ This has been due to the capability of MS to take proteomics to a higher throughput platform, allowing global proteome analyses and the generation of proteomics data repositories. ${ }^{[2,3]}$ This has brought us to an exciting era, wherein the use of MS for the targeted quantification of protein(s) of interest (hence the name "targeted") is emerging. Targeted proteomics, with its high accuracy, multiplexing capabilities, and reproducibility, has the potential to create a paradigm shift in the choice of techniques for protein quantification. ${ }^{[4]}$

A. Arora, Prof. K. Somasundaram

Department of Microbiology and Cell Biology

Indian Institute of Science

Bangalore 560012, India

E-mail: skumar1@iisc.ac.in; ksomasundaram1@gmail.com

DOI: 10.1002/bies.201800042
The development of cutting-edge genomics to achieve the Holy Grail in terms of disease predictions and therapeutics has proven to be successful in various fields. Where the underlying causes were genetic, it did exceedingly well regarding diagnosis and, to some extent, treatment. ${ }^{[5-7]}$ However, it is well established that the proteome of a cell provides better dynamic manipulation over space and time as compared to genomics and transcriptomics readouts. Indeed, proteins are the macromolecules that ensure most of the cellular functions and confer new adaptations. ${ }^{[8,9]}$ These adaptations caused by changes in protein abundance, post-translational modification, and conformation are key factors for many complex diseases, such as cancer, diabetes, and Alzheimer's disease. ${ }^{[10,11]}$ Although measuring these changes has been very useful for providing insights into the physiopathology of these diseases and in monitoring/targeting their driver factors, protein quantification by traditional methods has faced challenges due to limitations such as specificity and variation. This has restricted the progress of research and translational transfer in spite of the enormous advances the field has seen. ${ }^{[12]}$ Targeted proteomics provides a unique opportunity to overcome these challenges. Accordingly, it is not wrong to say that next-generation genomics arrived and has flourished exactly at the right time to support next-generation proteomics, which is on the verge of penetrating basic research and the clinics. ${ }^{[13]}$

Here, we discuss the advantages of targeted proteomics compared to other methods. We also provide principles of designing and performing targeted proteomics in a simplistic way to enthuse the readers to weigh in the advantages of targeted proteomics over traditional methods of protein quantification. Next, we discuss the promising future of targeted proteomics at the benchside and bedside with the mention of a few recent exemplary studies that demonstrate the impact that targeted proteomics can have on basic and translational research. These facts should persuade us of the required widespread acceptability of this technique in the coming future. We also present in detail three new emerging areas, where unreserved incorporation of targeted proteomics by diverse research communities is required for their successful utilization. Additionally, the limitations and difficulties associated with the acceptance of this technique for 
mainstream usage are also discussed. The important terminologies used in this article are shown in Box 1.

\section{From Shotgun to Targeted Proteomics}

As mentioned above, accurate quantification of a protein or a panel of proteins, as well as its interactions and modifications, is essential to understand the biology behind a disease or to monitor its progression and response to treatment. Quantification can be either relative to any control condition or absolute with the exact amount and stoichiometry in a particular sample. ${ }^{[14-16]}$ The design of the assay and the cost differ between these two settings. While the purpose of shotgun proteomics (also known as discovery approach) is to profile samples from various conditions and compare them for the differential abundance of proteins in an unbiased, nondirected manner, targeted proteomics focuses on the quantification of one or a set of protein(s) of interest. ${ }^{[17-19]}$ For example, in order to find candidate biomarkers for a disease, a discovery approach is employed. However, to establish a protein as a biomarker in clinical settings, a targeted proteomics approach is the method of choice for its measurement across a large set of samples with high accuracy and reproducibility. Although both techniques can be used for quantitative comparisons, targeted proteomics provides an edge over discovery based. ${ }^{[20]}$

There is also an emerging third method, called dataindependent acquisition (DIA) or sequential window acquisition of all theoretical fragment-ion spectra (SWATH-MS), that combines the advantages of both shotgun and targeted proteomics. In this method, MS/MS data are acquired for all the peptides, while data analysis can be performed in a targeted manner postacquisition by extracting the information of the required peptide. ${ }^{[21-23]}$ However, for targeted proteomics to reach benchside and bedside, enormous effort is required from the research community, health policymakers, and vendors to produce the infrastructure and expertise at all levels in a cost- and user-friendly manner. This would remove bottlenecks and result in the translational success of proteomics research. ${ }^{[24,25]}$

\section{A Primer: If You Know Nothing About Targeted Proteomics}

Targeted proteomics uses a bottom-up approach which relies on the measurement of peptides. ${ }^{[26]}$ A specific and unique peptide(s) from a protein can act as a surrogate for protein

\section{Box 1. \\ Useful terms}

Proteoforms: All possible different molecular forms of an expressed protein.

Bottom up approach: Proteins are digested by proteases and thus obtained peptides are analyzed using LC-MS.

Top down approach: Intact proteins, without prior digestion are fragmented inside MS.

Targeted proteomics: Hypothesis driven measurement of protein of interest using MS.

Discovery/shotgun proteomics: Profiling the proteome at global level.

DDA (data-dependent acquisition): another name for discovery proteomics, as the method of acquisition depends upon the data.

SRM (selected reaction monitoring): a method of performing targeted measurement on the protein of interest, performed on a triple quadruple instrument wherein a selected peptide and its selected signature fragments are monitored.

PRM (parallel reaction monitoring): a method of performing targeted measurement on the protein of interest, performed on a hybrid instruments wherein a selected peptide and its all signature fragments are monitored.

DIA (data-independent acquisition): This method combines the advantage of DDA and SRM. All ion within a selected $\mathrm{m} / \mathrm{z}$ window are fragmented. Deconvolution of the data is done later to fetch the required information.

SWATH: Sequential window acquisition of all theoretical mass spectra. Synonym for DIA.

MRM: Multiple reaction monitoring is a commonly used acronym for SRM.

pSRM: Pseudo SRM, an acronym for PRM.

sSRM: Scheduled SRM is a method to monitor fragment ions when they are expected to appear depending upon their retention time. This results in increase in number of fragment ions measured in one single run.

Peptidomics: Peptidomics is study of endogenously produced protein fragments/peptides.

MSI (mass spectrometry imaging): Technique to investigate the spatial distribution of molecular analytes on tissue surfaces using mass spectrometry. 
quantification. The data acquired only for the selected peptide provides more sensitivity and accuracy. Additionally, it is worth noting that a targeted proteomics assay has several advantages over traditional immunoassays. With the use of targeted proteomics, it is possible to measure a protein and its proteoforms with no requirement of antibody. ${ }^{[11]}$ It also enables multiplexing with the possibility of measuring many proteins in a single analysis using one sample. Thus, it offers a way to perform high-throughput measurement. Further, it overcomes the major limitations of specificity and the time duration of assay development, which are typical problems in traditionally used antibody-based protein quantification assays such as Western blotting and enzyme-linked immunosorbent assay (ELISA). Of what does the targeted proteomics assay consist? A simple illustration of quantification by targeted proteomics is provided (Figure 1). In this illustration, we provide a journey of your protein of interest (YPI) from a complex protein mixture through the mass spectrometer during the course of a targeted proteomics assay. The protein (YPI) digested by trypsin in the complex sample yields tryptic peptides (Y, P, and I). ${ }^{[27]}$ Peptides that are unique to the protein (peptides $\mathrm{Y}$ and $\mathrm{P}$ ), which are ionized in a reproducible manner (peptide Y), are selected for the assay. ${ }^{[28-30]}$ The tryptic peptides of a complex mixture of proteins are first processed through liquid chromatography (LC). Based on their physicochemical properties and the chromatographic gradient of the aqueous and organic phase, the detachment and elution of the peptides from the column provide them with a specific retention time..$^{[30-32]}$ However, as the samples dealt with are complex, coelution with other peptides cannot be avoided even with the best chromatographic systems. ${ }^{[33]}$ Peptides separated in the LC system are introduced sequentially in the mass spectrometer where they are ionized.

There are two widely used targeted proteomics approaches: selected reaction monitoring (SRM) and parallel reaction monitoring (PRM). ${ }^{[28,34]}$ In both of these methods, the first quadrupole is used as a filter to select the peptide (peptide Y), as a precursor ion, to fragment it further. This step is the most distinctive step of targeted proteomics since only the selected peptides are allowed to proceed and the corresponding data are acquired. Typically, SRM is performed on a triple quadrupole instrument. In the second quadrupole, the selected peptide (peptide Y) is fragmented through collusion-induced

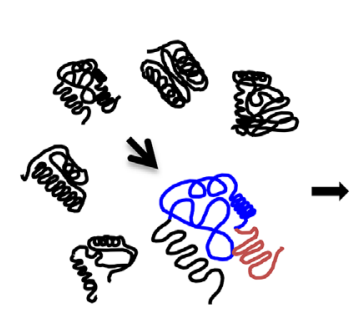

Protein YPI

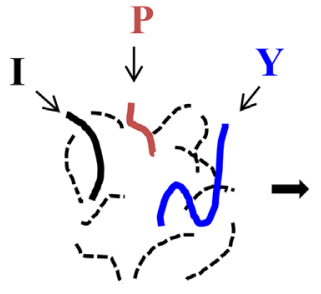

Tryptic Digestion

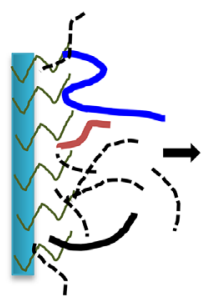

Adsorption on LC

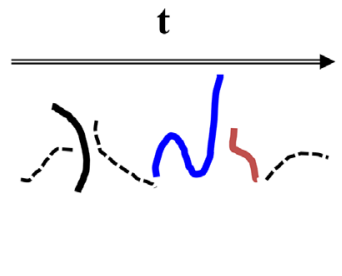

Desorption from LC

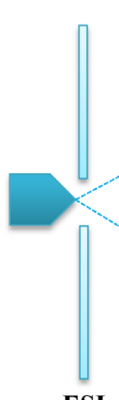

ESI

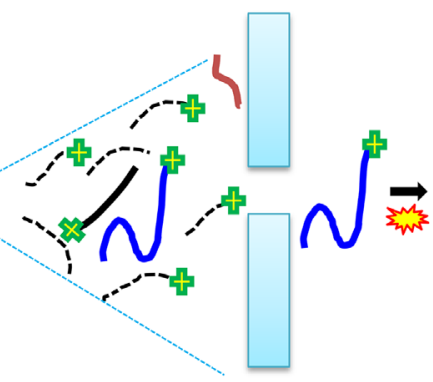

Q1

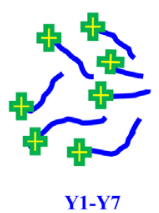

Q2

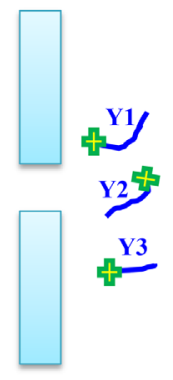

Q3

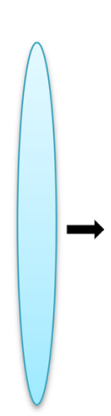

Detector

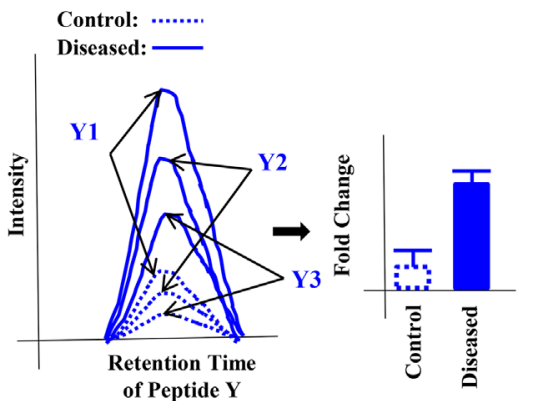

Figure 1. Illustration depicting selected reaction monitoring. This illustration demonstrates the journey of a selected peptide during an SRM assay performed for the quantification of your protein of interest (YPI). A complex sample is depicted by a few black-colored proteins in their tertiary structure. YPI is zoomed and shown as consisting of three different tryptic peptides. Upon tryptic digestion, all the proteins present are cleaved into peptides. Peptides formed from other proteins are shown as dotted lines, whereas for YPI, three different peptides generated (black, blue, and red) are shown as a bold line. Out of three tryptic peptides of YPI, only $Y$ and $P$ are unique (blue and red), while I is not (black). The peptide mixture first enters the liquid chromatography (LC) column, where most of the peptides in the aqueous phase bind to the reverse phase C18 column, but as the organic phase of the gradient increases, desorption and elution starts, which provides a specific retention time to the peptides. Peptides from LC enter the mass spectrometer, where electron spray ionization (ESI) renders a charge on the incoming analytes, making them ionized, which is shown by a single positive sign on peptides depicting single or multiple charges. In SRM, the selected ionizable unique peptide (Peptide Y) is allowed to proceed to the Q2 collision cell through quadrupole one (Q1), which serves as a mass filter towards quadrupole two (Q2). In Q2, peptide $\mathrm{Y}$ undergoes collision-induced dissociation, giving rise to its signature fragment ions $Y 1-Y 7$. In the next step, quadrupole three (Q3) serves as a mass filter and allows selected fragment ions (Y1-Y3) to proceed toward the detector. The intensity of fragment ions in different conditions provides quantitation of a protein (YPI). The average of ratio of intensity of $Y 1$ (diseased/control), $Y 2$ (diseased/control), and $Y 3$ (diseased/control) is used to represent results for differential abundance. 
dissociation to generate its signature fragment ions (Y1-Y7). Further, specific fragment ions (Y1, Y2, and Y3, also called transitions) are selected by the third quadrupole and are detected by the mass analyzer. In contrast, PRM is performed on a highresolution hybrid instrument, such as the quadrupole-ion trap (Q-Trap) and the hybrids quadrupole-time of flight (QqTOF) and quadrupole-Orbitrap (Q-Exactive), where all possible fragment ions are monitored by the mass analyzer. Ultimately, in a targeted proteomics assay, the area integrated under the fragment ion peaks is a measurement of the abundance of the fragment ions (Y1, Y2, and Y3), from which the precursor ion (peptide Y) and thus the protein (YPI) can be quantified (Figure 1) using dedicated software such as Skyline (https:// skyline.ms/project/home). ${ }^{[35,36]}$

The decision for correct peptide selection is made by obtaining information from discovery-based experiment and online repositories (Peptide Atlas; http://www.peptideatlas.org/, Global Proteome Machine Database; http://www.thegpm.org/ gpmdb/index.html and PRIDE; http://www.ebi.ac.uk/pride/). The selected peptide should be unique to the protein and reproducibly digested and ionized. The selection of fragment ions can again be made either by using previously acquired MSMS data or the available prediction tools (MRMaid; http://elvis. misc.cranfield.ac.uk/mrmaid/, SRMAtlas; http://www.srmatlas. org/). ${ }^{[3]}$ After shortlisting peptides and their fragment ions, the use of synthetic candidate peptides for optimizing the assay parameters and selection of best transitions is required. ${ }^{[28-30]}$

For data analysis, a quality fragment ion peak, consisting of a good number of data points, provides confident quantification. The number of points on a peak is decided by how much time an instrument spends detecting a particular ion. This time spent to measure an ion is called dwell time and the total amount of time between each measurement is called cycle time. The interplay between the dwell and cycle times, which are predefined, decides the number of peptides and proteins measured in one experiment. An increase in the number of fragment ions to be monitored reduces the dwell time per ion, which affects the data quality. ${ }^{[28]}$ Separation by LC, providing a specific retention time window for the peptide, allows the measurement of $\approx 100$ transitions in a single analysis. A known concentration of isotopically labeled synthetic peptide can be used to reduce false positives, for normalization, and for absolute measurements across the samples.

\section{Targeted Proteomics: What Does it Bring for Researchers at Benchside?}

In research laboratories, the measurement of proteins and their proteoforms is a very common practice. These measurements help to answer various biological questions, including dynamic changes in signaling pathways, finding condition-specific interactomes, or deciphering structural and conformational changes. The extensive use of the Western blot technique and ELISA over the years emphasizes the importance of protein measurements for data collection and for the representation of the above-mentioned research problems. However, sometimes antibody-based techniques fail to provide a clear answer due to their limitations, such as lack of specificity or unavailability.
Advancements in research tools and techniques have removed previous hurdles, so that age-old problems can be readdressed. ${ }^{[12]}$ Targeted proteomics is one such technique, which is at our doorstep with the promise that what we could not measure then, we can try now.

There are research groups dedicatedly working in the fields of both discovery and targeted proteomics. Several proofof-principle studies are being carried out worldwide, demonstrating the ability of proteomics to replace old techniques as well as improvements in sample preparation, instrumentation, and data analysis algorithms. ${ }^{[38]}$ In fact, a huge amount of data on these aspects is publicly available. ${ }^{[38]}$ These remarkable contributions have simultaneously inspired two different types of research. Firstly, many pioneering research groups in their specific areas are now ready to utilize targeted proteomics to bring more reproducibility and ease of use to their experiments. Secondly, the areas less explored earlier, due to certain limitations, are emerging with possibilities to uncover new concepts of biology. While it is true that Western blot has been used traditionally to perform the measurement of various proteoforms of proteins involved in a signaling pathway, it is often difficult to measure all of those forms simultaneously. The use of reverse phase protein arrays (RPPA) have made this possible to some extent, but it also faces the limitations of antibody specificity and availability. With targeted proteomics, a new approach to this problem has been realized. For instance, in yeast, a list of sentinel proteins (proteins reported for the active state of any biological process) was compiled based on various criteria. A total of 157 sentinel proteins and 152 sentinel phosphopeptides were measured simultaneously using multiple reaction monitoring (MRM). ${ }^{[39]}$ In another effort to establish a high-throughput MRM study, breast-cancer-related cell lines were subjected to MRM-based quantitation of 319 proteins that clustered the cells into clinically relevant subtypes. The approach was also found to be complementary to mRNA-based clustering, as the same mRNA and proteins did not categorize similar subtypes. ${ }^{[40]}$ To measure specific signaling or molecules of interest, a small assay with a set of proteins can be assessed. For example, it is difficult to perform GTPase activity measurement for different but closely related forms due to the lack of specific antibodies. An MRM assay to measure 12 different isoforms of GTPase simultaneously in the presence of agonists or inhibitors was developed and utilized. ${ }^{[41]}$ Thus, there are a significant number of studies available now, which have been reviewed in other articles, that provide us with a complete picture of current applications of targeted proteomics in different areas of biology. ${ }^{[42]}$ These successful attempts provide a proof of principle to take a leap into what is required to be studied regardless of the availability of the reagents. This also provides a huge opportunity to academia and companies to develop and provide consumables required to implement these assays. For example, it is possible to make a genome-wide peptide library covering a large set of proteins and their proteoforms, analogous to the siRNA/shRNA and CRISPR libraries used in genomics. Thus, a vision for the next-generation targeted proteomics era can be foreseen.

We envision a time will come sooner or later when targeted proteomics will be a routine practice for the relative comparison of proteins between conditions of interest in research laboratories. Each laboratory would have a custom-made peptide library 
for a set of targeted proteomics assays in line with their research interest. Probing a panel of proteins of signaling pathway activation cascades would be possible using a single run of MS. Other requirements, such as absolute quantification of proteins as well as studying protein-protein interactions and their complex stoichiometry, could be possible with the added ease of doing these experiments using relatively less sample quantity and with more confidence in the results. The design of assays and their standardization is already available for many proteins in repositories (http://assays.cancer.gov/), ${ }^{[43]}$ and with time, selecting desirable assays would become as easy as finding a correct antibody for your protein (Oh! that's a cliché).

Next, we discuss about proteoforms, peptidomics, and mass spectrometry imaging, which are three emerging fields that are likely to greatly benefit from targeted proteomics.

\subsection{Proteoforms: Targeted Proteomics for the Rescue of Ignored Forms}

Proteoforms signify the different molecular forms of a protein produced from a single gene as a result of genetic sequence variations (mutations and polymorphism), alternative splicing, RNA editing, post-translational modifications, and inteins. ${ }^{[11]}$ Thus, a protein can be redefined as a set of proteoforms. ${ }^{[44]}$ Proteoforms play a crucial role in imparting a level of complexity to living forms that cannot be explained by the genome output alone. ${ }^{[4,46]}$ The synthesis of different proteoforms for a given protein can lead to alterations in its activity, stability, and interactome. Additionally, the functional roles of proteoforms can be as different as proteins coded from entirely different genes. ${ }^{[4]}$ Overall, proteoform quantification would provide a dynamic reflection of proteomes to represent at what state the proteins are present inside the cells during health and disease.

Proteomics primarily relies on amino acid sequence identity. Due to the similarity in the sequences that the proteoforms share, they are mostly indistinguishable at the level of the discovery phase as well as in a targeted proteomics experiment if not designed carefully. For instance, consider a gene that encodes two proteoforms formed due to differential splicing, wherein one is functional while the other is a nonfunctional form. In this case, the quantitation based on a peptide common to both proteoforms will give a summed quantitation of both forms but miss out the important biology behind it. Therefore, the key is to know beforehand the existence of such proteoforms through genomics. ${ }^{[48]}$ Once this information is acquired, tools to distinguish the proteoforms and to quantitate them separately are needed. Antibody-based techniques are successful in quantitating post-translationally modified proteins but are limited to a few "famed" proteins and modifications. In such a scenario, it is now possible that a targeted proteomics experiment can be designed with precursor peptides to be measured specific to proteoforms. Targeted-proteomics-based experiments have been employed successfully for the measurement of post-translational modification of proteins, in particular, phosphorylation. ${ }^{[49,50]}$ With the increased use of targeted proteomics, it is possible to explore the repertoire of hundreds of different types of post-translational modifications which might play an important role in cell functioning that are yet to be discovered. ${ }^{[51,52]}$ Similarly, there is a vast amount of literature now available for single nucleotide polymorphism (SNP) variants and their role in deciding the response and predisposition to disease in a population-specific way. ${ }^{[53]}$ Although their presence is widely monitored through genomic studies, their functional relevance is less studied. SNPs that give rise to single amino acid polymorphism (SAP) have the potential to alter protein function. ${ }^{[54]}$ By measuring peptides specific to SAP variants, this area can gain impetus. Another source of proteoform generation is the RNA editing phenomenon, in which a new layer of diversity is added in the proteoform variety. ${ }^{[55]}$ Measurement of endogenous proteins derived from edited transcripts have not been reported to our knowledge, as the studies till now mostly report the measurement of edited transcripts. ${ }^{[56-58]}$ Using targeted proteomics with assays designed specifically to the edited and unedited peptide can give RNA edited proteoform ratios in terms of their abundance at the protein level. Another less popular molecular form is inteins, which are formed as a result of protein splicing. ${ }^{[59]}$

Although the initial requirement is cataloging the proteoforms using global approaches, the next step requires establishment of the presence of specific proteoforms using a targeted proteomics approach, through which more functional insights can be obtained. ${ }^{[60]}$ The significance of all these proteoforms in biomedical science can emerge with thrilling possibilities to find their unknown association with disease progress and etiology. This is possible if and only if the vast diversity of proteoforms can be realized and measured.

\subsection{Peptidomics: Targeted Proteomics for Annotated or Unannotated}

Peptidomics, the study of endogenously produced peptides, is another emerging area that requires the utmost attention and can benefit the most from the integration of targeted proteomics. ${ }^{[61-63]}$ The discovery-based approach relies on the annotated sequence information bestowed by genomics for the successful identification of proteins. However, this approach leaves behind hundreds of peptides which do not match to any theoretically deduced peptides in the protein databases. This peptide pool could be as a result of the absence of the protein sequence in the database or because of the mass shift as a result of modifications that are not included during the database search. Another possibility is that these peptides are not present as a part of proteins at all. The origin of these peptides can be broadly categorized into two types: first as a by-product of the maturation and degradation cycle of a protein, secondly as a result of translation of short open reading frames (sORFs) present within both coding and noncoding regions. Above 10 lakh sORFs have been identified in humans, which emphasizes on the role of sORFs in cells. ${ }^{[64]}$

These two classes of peptides are now acknowledged to be present in the cell but with rare functional annotation. ${ }^{[65-67]}$ The likely reason for this disparity is the lack of tools to measure the presence and activity of these peptides. While there is emerging literature regarding the structural roles played by noncoding 
RNAs to inhibit or activate proteins, it is even more feasible for small peptides capable of mimicking folds and turns of a protein, which can easily block the active site or result in a change of confirmation. ${ }^{[68,69]}$ These peptides can also serve as biomarkers to analyze the presence of a diseased state or response toward various stress conditions. ${ }^{[70]}$ If these possibilities are true, there is a requirement of understanding their origin, regulation, and function. While identifying the existence of these peptides is the first step that comes from discovery proteomics or the most promising SWATH data, their measurement on a routine basis in laboratories requires tools such as MRM. An example of this is a recent study wherein MRM was utilized for the validation of identified sORFs. ${ }^{[71]}$ Thus, targeted proteomics increases the proteome space accessible for measurement.

\subsection{Mass Spectrometry Imaging: Targeted Proteomics to Look Inside the Microscope}

The visualization of cells and tissue organization under the microscope to obtain their characteristics was one of the first benchmarks in biology. This field has grown tremendously from the time of Hook's microscope to the invention of highresolution microscopy. The quantitation and localization of biological macromolecules within cells in different conditions are equally important. ${ }^{[72]}$ The special arrangement inside the cells provides an emergent property to the biomolecules. The fluorescent-tagged antibody specific to proteins has been the major tool for localization studies. ${ }^{[73]}$ Recently, the integration of mass spectrometry with imaging has given rise to a new field of mass spectrometry imaging (MSI). ${ }^{[74,75]}$ Utilizing MSI, various types of biomolecules, including proteins and lipids, can be mapped over the surface being visualized under the microscope. Till now, major advancements have been in the profiling-based approach with a combination of microscopy and matrixassociated laser desorption and ionization (MALDI) or secondary ionization mass spectrometry (SIMS).$^{[74,76]}$ An integration of microscopy and MRM is a promising combination for the measurement of a specific set of proteins on the histopathological tissue of a diseased condition.

MSI is particularly useful for the localization/quantitation of certain proteins, wherein immunostaining-based methods have not been successful due to the unavailability of immunohistochemical-grade antibodies. With the growing field of immunotherapeutics in cancer biology, the study of immune cell infiltrations in solid tumors has gained attention. There is an interest in the localization information of different nonmalignant cell types to decipher the components of the specialized niche provided to the malignant cells. ${ }^{[77]}$ MRM assays can be designed for various cell markers that can unravel the composition of the microenvironment with the information regarding their localization. Similar efforts have been made by using mass cytometry (CyTOF) using antibody-based recognition of different cell types and their identification by MS, but this technique lacks localization information. ${ }^{[78]}$ Hence, targetedproteomics-based identification of cell types and proteins present in the tissue section can enlighten the clinical research area, thus overcoming many limitations of histopathology.
There are limitations to this approach, as the sample retrieved from a particular location of the tissue section is scarce. However, with advancements in laser dissection microscopy, we hope that MSI involving targeted proteomics of specific regions will definitely have the potential to accelerate the pace of research in this area.

\section{Targeted Proteomics: What Does it Bring to Patients at Bedside?}

In clinics, day-to-day diagnosis of various diseases includes biochemical tests, protein quantification, microscopic observations, and genomic analysis. Unfortunately, there are very few Food-and-Drug-Administration-approved MS-based tests used in clinics. For targeted proteomics to become an integrated part of daily diagnostics and decision-making in clinics, comprehensive information has to be generated in preclinical studies. Guidelines are now available for the robust development and preclinical establishment of targeted proteomics assays. The translational transfer of the developed assays is subjected to stringent criteria by regulatory authorities, which has provided a framework for researchers to work. ${ }^{[24,79,80]}$

Targeted assays for future clinical use mainly consist of biomarkers in body fluids or tissue samples and therapeutic targets. Many candidate body fluid biomarkers for clinical diagnosis, prognosis, and therapeutic monitoring have been established by performing discovery-based experiments. ${ }^{[81-83]}$ Paradoxically, the number of approved clinical markers falls short of the efforts made to identify them. The caveat occurs at the stage of validation of these biomarkers in larger cohorts. ${ }^{[84]}$ The important step of quantitative validation of biomarkers requires the establishment of targeted proteomics assays, as they can transform the speed and cost of implementation in clinical settings. ${ }^{[79]}$ In fact, MRM assays for known biomarkers, as well as for proteins known to be associated with diseased conditions, have been developed recently, but they are yet to be transferred to clinics. ${ }^{\left[{ }^{85}-88\right]}$ A recent review discussed using the targeted proteomics approach for the measurement of circulating insulin growth factor-1 (IGF1) for routine performance in clinical settings. ${ }^{[89]}$ Similarly, the development of MRM assays in the field of cancer clinical management, pathogen diagnosis, and widespread chronic diseases such as diabetes would help to bring targeted proteomics in practice in the near future. ${ }^{[38,90]}$

Formalin-fixed, paraffin-embedded (FFPE) tissue samples are routinely used for diagnostic and classification purposes using traditional antibody-based staining. Recent reports have demonstrated the use of targeted proteomics to measure markers associated with aggressive cancers using FFPE. ${ }^{[1]}$ When this method becomes mainstream, a vast amount of stored FFPE samples in clinics can be used. ${ }^{[92]}$ Similarly, quantitative measurement of drug-metabolizing enzymes and transporters using targeted proteomics can provide insights and monitoring of the longitudinal therapeutic response of patients. ${ }^{\text {[9-95] }}$

With the potential to replace many other diagnostic methods, targeted proteomics could be an all-in-one "combo" technique for future clinical diagnoses. Targeted proteomics would bring with it multiplexing, which reduces the required sample quantity. The multiplexing capability of targeted proteomics is 
well suited for clinics, where availability of samples is limited by its amount. ${ }^{[96]}$ It might help to solve some problems with the cold chain (freezing temperature is a must for tertiary protein structure), as a stable peptide can be chosen for developing the assay, making it easier for sample transportation. In addition, assays can be developed for target antigens for which tests are not available at present because of technical issues.

For targeted assays to reach the bedside, in addition to regulatory criteria required at the experimental and preclinical levels, a parallel development of exhaustive infrastructure is required. The Clinical Proteomics Tumor Analysis Consortium (CPTAC), the initiative established by the National Cancer Institute (NCI), is one such example of large-scale clinical proteomics data management towards the association of disease characteristics with proteomics. ${ }^{[97]}$ For generation and utilization of similar data at extended clinical levels, this infrastructure should progress in two areas: instrumentation (hardware) and data analysis (software). The instruments currently used for targeted proteomics are for dedicated research laboratories and must be handled by experts in MS, so their widespread implementation requires additional efforts to make them more user friendly and cost effective. For data analysis, cloud-based knowledge storage and computation can create architecture that can make targeted proteomics assays readily accessible and easy to interpret at clinics. ${ }^{[98]}$ This strategy has the potential to be extended as a service for providing remote data analysis. This information, in a confidential and secure way, can be passed on to the pathological labs associated with hospitals in the field to provide the requisite and well-formatted information to the medical practitioner for decision-making. ${ }^{[9]}$ Thus, targeted proteomic assays can be brought to the bedside as a powerful tool for disease diagnosis, prognosis, patient follow-up, and disease screening.

\section{Limitations of Targeted Proteomics}

The translation of targeted proteomics in regular practice at benchside and bedside, although promising, faces daunting challenges. The major roadblock is the expertise available for maintenance and operation of mass spectrometers in hospitals and research settings. While many training options are available, they are opted for by those who are in the process of doing proteomics experiments. More education is needed about its advantages over other techniques so that the instrumentation becomes more available and more people can be trained. Additionally, making the instrumentation more user friendly is another area that can accelerate this process.

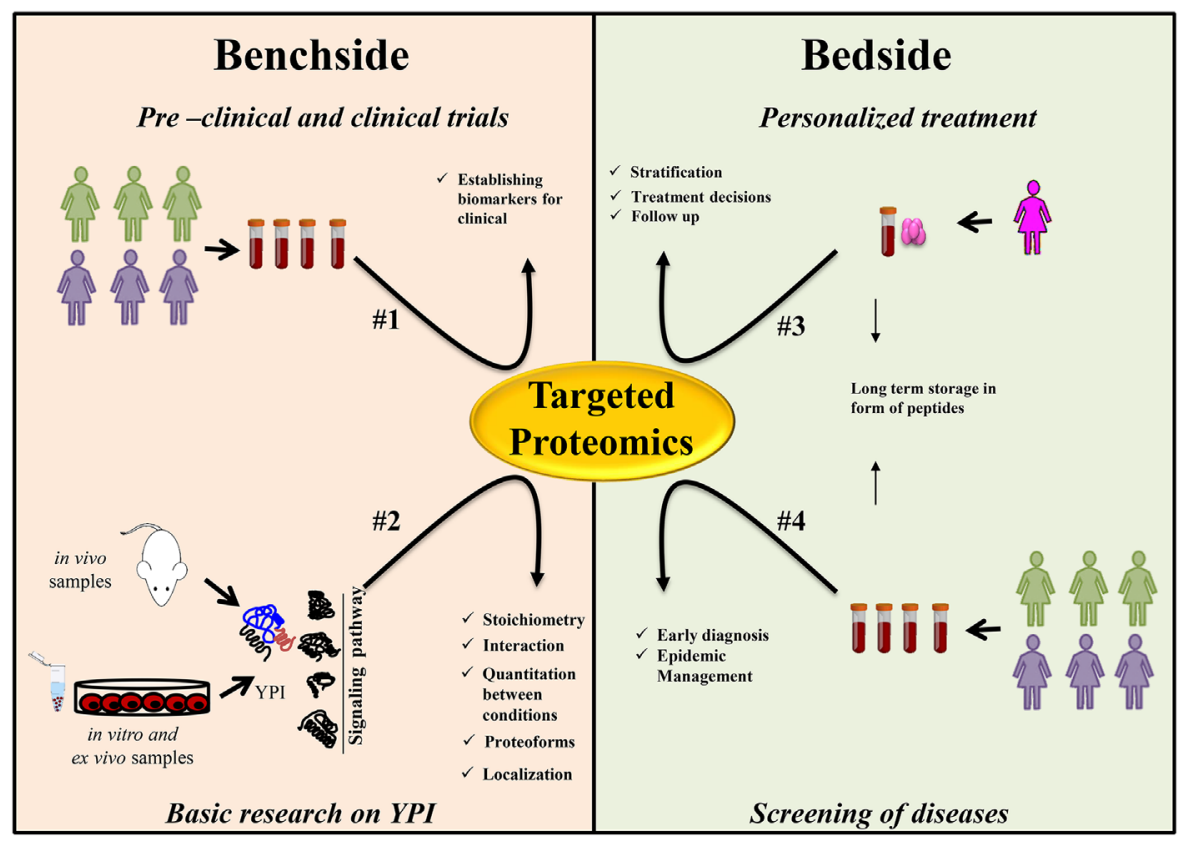

Figure 2. Vision of targeted proteomics at the benchside and bedside. Targeted proteomics assay for: \# 1 validation and preclinical trial for biomarker panels for disease diagnosis, prognosis, and treatment predictions; \#2 your protein of interest (YPI) with the possibility of measuring different proteoforms under different conditions or a signaling pathway by measuring multiple constituent proteins in their active form; \#3 already approved a panel of proteins established for stratifying patients into two groups, such as responder or nonresponder, for treatment; \#4 already approved a panel of proteins established for diagnosis and screening of diseases such as cancer or malaria, the differential diagnosis for different serotypes of causative agent, or stage of a disease. Symbols used: 1 : body fluid sample, 0 : tissue sample biopsy, 10 : control sample population; diseased sample population, in: person specific treatment. 
In terms of analytical issues, targeted proteomics also faces certain barriers. In many cases, sample enrichment is essential to determine the quantity of the target protein. When it comes to clinical use, enrichment is not always possible due to limitations such as sample quantity. In such cases, usage of targeted proteomics becomes difficult. Another important challenge in adopting targeted proteomics for routine use is the analysis and interpretation of the targeted proteomics data. Here, again, expertise is limited and additionally rigorous training is required to handle such data. The development of bioinformatics tools to overcome these limitations is needed and they should also be freely accessible. Efforts from experts in the field are appreciable, who have provided free access to applications such as Skyline along with access to instructional videos and a support board (http://proteome.gs.washington.edu/software/skyline). Overall, technical development is going in the right direction and has great potential, but more efforts are needed to make it a mainstream process.

\section{Conclusions}

Recent advances in the field of targeted proteomics have made it a feasible technique and have changed the perspective of researchers regarding its use in laboratories all over the world. With repositories being actively developed and analysis made accessible in terms of software, the transition from research on the development of the assay and technique to its daily usage to answer day-to-day research questions is foreseeable. There are many emerging fields where incorporation of targeted proteomics could make a huge difference in their progress. For example, studying specific proteoforms, peptides that are not annotated to proteins, and localization of proteins on tissue sections for which compatible antibodies are unavailable have always been challenging. With targeted proteomics integration in the experimental design to solve such questions, it becomes more of an analytical challenge than a technical issue. With ongoing improvements in the targeted proteomics, these analytical challenges could soon be handled. This would be possible with the contribution of researchers and companies to make the techniques and data analysis more reproducible and user friendly on various platforms. This gives us hope for the introduction of targeted proteomics to the benchside in the near future (Figure 2).

In terms of clinical use, a full consideration of guidelines and training at various levels is required. The benefits of using targeted proteomics at the bedside are clear. This method has the potential to bring translational research into action and to make personalized medicine a reality. Efforts are required to build the infrastructure at clinics in terms of instrumentation, expertise, and data analysis. The reciprocal, smooth, and real-time transfer of data to experts for data analysis over the cloud and the return of this information to clinicians will overcome the biggest hindrance for generalized use in clinics (Figure 2).

Overall, the targeted proteomics approach is gaining momentum to be an integral part of basic research and clinics. For this to happen in an acceptable timeline, the method needs to be more accessible and easier to use. ${ }^{[100]}$ Automation at various steps, such as sample processing, instrument handling, and data analysis, is crucial for achieving this task. Assay development and reagent availability for well-known signaling pathway proteins and biomarkers already in use will provide the impetus to progress as a proof of principle for the advantages of this technique. Once targeted proteomics becomes mainstream, a metamorphosis of protein quantification should occur.

\section{Abbreviations}

ELISA, enzyme-linked immunosorbent assay; LC, liquid chromatography; MS, mass spectrometry; PRM, parallel reaction monitoring; SRM, selected reaction monitoring.

\section{Acknowledgments}

The authors thank Dr. Phillip Marin, Institute for Functional Genomics, CNRS UMR 5203, INSERM U1191, Université de Montpellier, France for his critical review of the manuscript. K.S. acknowledges CSIR, DST, and DBT, Government of India for research grants, as well as the Indo-French Centre for the Promotion of Advanced Research (Grant no: 5603-1). Infrastructure support by funding from DST-FIST, DBT grant-in-aid, and UGC (Centre for Advanced Studies in Molecular Microbiology) to MCB is acknowledged. K.S. is a JC Bose Fellow of the Department of Science and Technology. A.A. acknowledges IISc for the fellowship.

\section{Conflict of Interest}

The authors declare no conflict of interest.

\section{Keywords}

mass spectrometry, MRM, PRM, SRM, targeted proteomics

Received: March 6, 2018

Revised: November 28, 2018

Published online: February 8, 2019

[1] R. Aebersold, M. Mann, Nature 2003, 422, 198.

[2] T. Nilsson, M. Mann, R. Aebersold, J. R. Yates, 3rd, A. Bairoch, J. J. Bergeron, Nat. Methods 2010, 7, 681.

[3] Z. Zhang, S. Wu, D. L. Stenoien, L. Pasa-Tolic, Annu. Rev. Anal. Chem. 2014, 7, 427.

[4] R. Aebersold, A. L. Burlingame, R. A. Bradshaw, Mol. Cell. Proteom.: MCP 2013, 12, 2381.

[5] J. M. Heuckmann, R. K. Thomas, Ann. Oncol. 2015, 26, 1830.

[6] M. Might, M. Wilsey, Genet. Med. 2014, 16, 736

[7] G. M. Frampton, A. Fichtenholtz, G. A. Otto, K. Wang, S. R. Downing, J. He, M. Schnall-Levin, J. White, E. M. Sanford, P. An, J. Sun, F. Juhn, K. Brennan, K. Iwanik, A. Maillet, J. Buell, E. White, M. Zhao, S. Balasubramanian, S. Terzic, T. Richards, V. Banning, L. Garcia, K. Mahoney, Z. Zwirko, A. Donahue, H. Beltran, J. M. Mosquera, M. A. Rubin, S. Dogan, C. V. Hedvat, M. F. Berger, L. Pusztai, M. Lechner, C. Boshoff, M. Jarosz, C. Vietz, A. Parker, V. A. Miller, J. S. Ross, J. Curran, M. T. Cronin, P. J. Stephens, D. Lipson, R. Yelensky, Nat. Biotechnol. 2013, 31, 1023.

[8] Y. Liu, A. Beyer, R. Aebersold, Cell 2016, 165, 535.

[9] N. T. Ingolia, L. F. Lareau, J. S. Weissman, Cell 2011, 147, 789 
[10] R. Aebersold, J. N. Agar, I. J. Amster, M. S. Baker, C. R. Bertozzi, E. S. Boja, C. E. Costello, B. F. Cravatt, C. Fenselau, B. A. Garcia, Y. Ge, J. Gunawardena, R. C. Hendrickson, P. J. Hergenrother, C. G. Huber, A. R. Ivanov, O. N. Jensen, M. C. Jewett, N. L. Kelleher, L. L. Kiessling, N. J. Krogan, M. R. Larsen, J. A. Loo, R. R. Ogorzalek Loo, E. Lundberg, M. J. MacCoss, P. Mallick, V. K. Mootha, M. Mrksich, T. W. Muir, S. M. Patrie, J. J. Pesavento, S. J. Pitteri, H. Rodriguez, A. Saghatelian, W. Sandoval, H. Schluter, S. Sechi, S. A. Slavoff, L. M. Smith, M. P. Snyder, P. M. Thomas, M. Uhlen, J. E. Van Eyk, M. Vidal, D. R. Walt, F. M. White, E. R. Williams, T. Wohlschlager, V. H. Wysocki, N. A. Yates, N. L. Young, B. Zhang, Nat. Chem. Biol. 2018, 14, 206

[11] L. M. Smith, N. L. Kelleher, Consortium for Top Down, P., Nat. Methods 2013, 10, 186.

[12] A. M. Edwards, R. Isserlin, G. D. Bader, S. V. Frye, T. M. Willson, F. H. Yu, Nature 2011, 470, 163.

[13] G. M. Sheynkman, M. R. Shortreed, A. J. Cesnik, L. M. Smith, Annu. Rev. Anal. Chem. 2016, 9, 521.

[14] S. A. Gerber, J. Rush, O. Stemman, M. W. Kirschner, S. P. Gygi, Proc. Natl. Acad. Sci. USA 2003, 100, 6940.

[15] C. Ludwig, M. Claassen, A. Schmidt, R. Aebersold, Mol. Cell. Proteom.: MCP 2012, 11, M111013987.

[16] V. Brun, A. Dupuis, A. Adrait, M. Marcellin, D. Thomas, M. Court, F. Vandenesch, J. Garin, Mol. Cell. Proteom.: MCP 2007, 6, 2139.

[17] S. Matallana-Surget, B. Leroy, R. Wattiez, Exp. Rev. Proteom. 2010, 7,5 .

[18] V. Vidova, Z. Spacil, Anal. Chim. Acta 2017, 964, 7.

[19] B. Domon, R. Aebersold, Nat. Biotechnol. 2010, 28, 710.

[20] S. S. Faria, C. F. Morris, A. R. Silva, M. P. Fonseca, P. Forget, M. S. Castro, W. Fontes, Front. Oncol. 2017, 7, 13.

[21] E. Borras, E. Sabido, Proteomics 2017, 17, https://doi.org/10.1002/ pmic. 201700180

[22] S. I. Anjo, C. Santa, B. Manadas, Proteomics 2017, 17, https://doi. org/10.1002/pmic.201600278.

[23] R. Aebersold, A. Bensimon, B. C. Collins, C. Ludwig, E. Sabido, Proteomics 2016, 16, 2065

[24] S. A. Carr, S. E. Abbatiello, B. L. Ackermann, C. Borchers, B. Domon, E. W. Deutsch, R. P. Grant, A. N. Hoofnagle, R. Huttenhain, J. M. Koomen, D. C. Liebler, T. Liu, B. MacLean, D. R. Mani, E. Mansfield, H. Neubert, A. G. Paulovich, L. Reiter, O. Vitek, R. Aebersold, L. Anderson, R. Bethem, J. Blonder, E. Boja, J. Botelho, M. Boyne, R. A. Bradshaw, A. L. Burlingame, D. Chan, H. Keshishian, E. Kuhn, C. Kinsinger, J. S. Lee, S. W. Lee, R. Moritz, J. Oses-Prieto, N. Rifai, J. Ritchie, H. Rodriguez, P. R. Srinivas, R. R. Townsend, J. Van Eyk, G. Whiteley, A. Wiita, S. Weintraub, Mol. Cell. Proteom.: MCP, 2014 13, 907.

[25] L. C. Gillet, A. Leitner, R. Aebersold, Annu. Rev. Anal. Chem. 2016, 9, 449.

[26] K. A. Resing, N. G. Ahn, FEBS Lett. 2005, 579, 885.

[27] R. L. Gundry, M. Y. White, C. I. Murray, L. A. Kane, Q. Fu, B. A. Stanley, J. E. Van Eyk, Current Protocols in Molecular Biology. 2009, Ch. 10, Unit10 25, https://doi.org/10.1002/0471142727. $\mathrm{mb} 1025 \mathrm{~s} 88$

[28] V. Lange, P. Picotti, B. Domon, R. Aebersold, Mol. Syst. Biol. 2008, 4, 222.

[29] G. Vandemoortele, A. Staes, G. Gonnelli, N. Samyn, D. De Sutter, E. Vandermarliere, E. Timmerman, K. Gevaert, L. Martens, S. Eyckerman, Sci. Rep. 2016, 6, 27220.

[30] P. Mallick, M. Schirle, S. S. Chen, M. R. Flory, H. Lee, D. Martin, J. Ranish, B. Raught, R. Schmitt, T. Werner, B. Kuster, R. Aebersold, Nat. Biotechnol. 2007, 25, 125.

[31] D. Josic, S. Kovac, Current Protocols in Protein Science. 2010, Ch. 8, Unit 8 7. https://doi.org/10.1002/0471140864.ps0807s61.

[32] C. Escher, L. Reiter, B. MacLean, R. Ossola, F. Herzog, J. Chilton, M. J. MacCoss, O. Rinner, Proteomics 2012, 12, 1111.
[33] A. F. Jarnuczak, D. C. Lee, C. Lawless, S. W. Holman, C. E. Eyers, S. J. Hubbard, J. Proteome Res. 2016, 15, 2945.

[34] A. Bourmaud, S. Gallien, B. Domon, Proteomics 2016, 16, 2146.

[35] C. M. Colangelo, L. Chung, C. Bruce, K. H. Cheung, Methods 2013, 61, 287.

[36] B. MacLean, D. M. Tomazela, N. Shulman, M. Chambers, G. L. Finney, B. Frewen, R. Kern, D. L. Tabb, D. C. Liebler, M. J. MacCoss, Bioinformatics 2010, 26, 966.

[37] U. Kusebauch, D. S. Campbell, E. W. Deutsch, C. S. Chu, D. A. Spicer, M. Y. Brusniak, J. Slagel, Z. Sun, J. Stevens, B. Grimes, D. Shteynberg, M. R. Hoopmann, P. Blattmann, A. V. Ratushny, O. Rinner, P. Picotti, C. Carapito, C. Y. Huang, M. Kapousouz, H. Lam, T. Tran, E. Demir, J. D. Aitchison, C. Sander, L. Hood, R. Aebersold, R. L. Moritz, Cell 2016, 166, 766.

[38] J. E. Van Eyk, F. J. Corrales, R. Aebersold, F. Cerciello, E. W. Deutsch, P. Roncada, J. C. Sanchez, T. Yamamoto, P. Yang, H. Zhang, G. S. Omenn, J. Proteome Res. 2016, 15, 3979.

[39] M. Soste, R. Hrabakova, S. Wanka, A. Melnik, P. Boersema, A. Maiolica, T. Wernas, M. Tognetti, C. von Mering, P. Picotti, Nat. Methods 2014, 11, 1045.

[40] J. J. Kennedy, S. E. Abbatiello, K. Kim, P. Yan, J. R. Whiteaker, C. Lin, J. S. Kim, Y. Zhang, X. Wang, R. G. Ivey, L. Zhao, H. Min, Y. Lee, M. H. Yu, E. G. Yang, C. Lee, P. Wang, H. Rodriguez, Y. Kim, S. A. Carr, A. G. Paulovich, Nat. Methods 2014, 11, 149.

[41] C. C. Zhang, R. Li, H. Jiang, S. Lin, J. C. Rogalski, K. Liu, J. Kast, J. Proteome Res. 2015, 14, 967.

[42] N. P. Manes, A. Nita-Lazar, J. Proteom. 2018, https://doi.org/ 10.1016/j.jprot.2018.02.008.

[43] J. R. Whiteaker, G. N. Halusa, A. N. Hoofnagle, V. Sharma, B. MacLean, P. Yan, J. A. Wrobel, J. Kennedy, D. R. Mani, L. J. Zimmerman, M. R. Meyer, M. Mesri, H. Rodriguez, C. Clinical Proteomic Tumor Analysis, A. G. Paulovich, Nat. Methods 2014, 11, 703.

[44] L. M. Smith, N. L. Kelleher, Science 2018, 359, 1106.

[45] K. D. Pruitt, T. Tatusova, D. R. Maglott, Nucl. Acids Res. 2007, 35, D61.

[46] N. A. O'Leary, M. W. Wright, J. R. Brister, S. Ciufo, D. Haddad, R. McVeigh, B. Rajput, B. Robbertse, B. Smith-White, D. Ako-Adjei, A. Astashyn, A. Badretdin, Y. Bao, O. Blinkova, V. Brover, V. Chetvernin, J. Choi, E. Cox, O. Ermolaeva, C. M. Farrell, T. Goldfarb, T. Gupta, D. Haft, E. Hatcher, W. Hlavina, V. S. Joardar, V. K. Kodali, W. Li, D. Maglott, P. Masterson, K. M. McGarvey, M. R. Murphy, K. O'Neill, S. Pujar, S. H. Rangwala, D. Rausch, L. D. Riddick, C. Schoch, A. Shkeda, S. S. Storz, H. Sun, F. ThibaudNissen, I. Tolstoy, R. E. Tully, A. R. Vatsan, C. Wallin, D. Webb, W. Wu, M. J. Landrum, A. Kimchi, T. Tatusova, M. DiCuccio, P. Kitts, T. D. Murphy, K. D. Pruitt, Nucl Acids Res. 2016, 44, D733.

[47] X. Yang, J. Coulombe-Huntington, S. Kang, G. M. Sheynkman, T. Hao, A. Richardson, S. Sun, F. Yang, Y. A. Shen, R. R. Murray, K. Spirohn, B. E. Begg, M. Duran-Frigola, A. MacWilliams, S. J. Pevzner, Q. Zhong, S. A. Trigg, S. Tam, L. Ghamsari, N. Sahni, S. Yi, M. D. Rodriguez, D. Balcha, G. Tan, M. Costanzo, B. Andrews, C. Boone, X. J. Zhou, K. Salehi-Ashtiani, B. Charloteaux, A. A. Chen, M. A. Calderwood, P. Aloy, F. P. Roth, D. E. Hill, L. M. lakoucheva, Y. Xia, M. Vidal, Cell 2016, 164, 805

[48] C. L. Nilsson, E. Mostovenko, C. F. Lichti, K. Ruggles, D. Fenyo, K. R. Rosenbloom, W. S. Hancock, Y. K. Paik, G. S. Omenn, J. LaBaer, R. A. Kroes, M. Uhlen, S. Hober, A. Vegvari, P. E. Andren, E. P. Sulman, F. F. Lang, M. Fuentes, E. Carlsohn, M. R. Emmett, J. R. Moskal, F. S. Berven, T. E. Fehniger, G. Marko-Varga, J. Proteome Res. 2015, 14, 603.

[49] S. L. Banerjee, U. Dionne, J. P. Lambert, N. Bisson, J. Proteom. 2018, https://doi.org/10.1016/j.jprot.2018.02.004 
[50] L. J. M. Dekker, L. Zeneyedpour, S. Snoeijers, J. Joore, S. Leenstra, T. M. Luider, J. Proteome Res. 2018, 17, 1654.

[51] Q. Kou, B. Zhu, S. Wu, C. Ansong, N. Tolic, L. Pasa-Tolic, X. Liu, J. Proteome Res. 2016, 15, 2422.

[52] T. Sajic, Y. Liu, E. Arvaniti, S. Surinova, E. G. Williams, R. Schiess, R. Huttenhain, A. Sethi, S. Pan, T. A. Brentnall, R. Chen, P. Blattmann, B. Friedrich, E. Nimeus, S. Malander, A. Omlin, S. Gillessen, M. Claassen, R. Aebersold, Cell Rep. 2018, 23, 2819.

[53] H. C. Lu, J. Herrera Braga, F. Fraternali, Bioinformatics 2016, 32, 2534.

[54] R. Cao, Y. Shi, S. Chen, Y. Ma, J. Chen, J. Yang, G. Chen, T. Shi, Nucl. Acids Res. 2017, 45, D827.

[55] X. Peng, X. Xu, Y. Wang, D. H. Hawke, S. Yu, L. Han, Z. Zhou, K. Mojumdar, K. J. Jeong, M. Labrie, Y. H. Tsang, M. Zhang, Y. Lu, P. Hwu, K. L. Scott, H. Liang, G. B. Mills, Cancer Cell 2018, 33, 817.

[56] M. F. Lanfranco, P. K. Seitz, M. V. Morabito, R. B. Emeson, E. Sanders-Bush, K. A. Cunningham, J. Neurosci. Methods 2009, 179, 247.

[57] K. Iwamoto, M. Bundo, K. Kasai, T. Kato, Biochem. Biokhimiia 2011 76, 912

[58] L. M. Roberson, J. J. Rosenthal, Rna 2006, 12, 1907.

[59] N. H. Shah, T. W. Muir, Chem. Sci. 2014, 5, 446.

[60] S. Elleuche, S. Poggeler, Appl. Microbiol. Biotechnol. 2010, 87, 479.

[61] M. L. Romero Romero, A. Rabin, D. S. Tawfik, Angew. Chem. 2016, 55, 15966.

[62] G. Menschaert, T. T. Vandekerckhove, G. Baggerman, L. Schoofs, W. Luyten, W. Van Criekinge, J. Proteome Res. 2010, 9, 2051.

[63] G. Rosenberger, Y. Liu, H. L. Rost, C. Ludwig, A. Buil, A. Bensimon, M. Soste, T. D. Spector, E. T. Dermitzakis, B. C. Collins, L. Malmstrom, R. Aebersold, Nat. Biotechnol. 2017, 35, 781.

[64] S. Savickas, U. Auf dem Keller, Biol. Chem. 2017, 399, 47.

[65] R. P. Hellens, C. M. Brown, M. A. W. Chisnall, P. M. Waterhouse, R. C. Macknight, Trends Plant Sci. 2016, 21, 317.

[66] V. Olexiouk, W. Van Criekinge, G. Menschaert, Nucl. Acid Res. 2018, 46, D497.

[67] J. P. Albuquerque, V. Tobias-Santos, A. C. Rodrigues, F. B. Mury, R. N. da Fonseca, Genet. Mol. Biol. 2015, 38, 278.

[68] E. Rivas, J. Clements, S. R. Eddy, Nat. Methods 2017, 14, 45.

[69] C. Y. Wu, Q. Z. Li, Z. X. Feng, Genomics 2016, 107, 9.

[70] Z. W. Lai, A. Petrera, O. Schilling, Biol. Chem. 2015, 396, 185

[71] J. Ma, C. C. Ward, I. Jungreis, S. A. Slavoff, A. G. Schwaid, J. Neveu, B. A. Budnik, M. Kellis, A. Saghatelian, J. Proteome Res. 2014, 13, 1757.

[72] M. C. Hung, W. Link, J. Cell Sci. 2011, 124, 3381.

[73] C. Stadler, E. Rexhepaj, V. R. Singan, R. F. Murphy, R. Pepperkok, M. Uhlen, J. C. Simpson, E. Lundberg, Nat. Methods 2013, 10, 315.

[74] M. Kompauer, S. Heiles, B. Spengler, Nat. Methods 2017, 14, 1156.

[75] M. K. Passarelli, A. Pirkl, R. Moellers, D. Grinfeld, F. Kollmer, R. Havelund, C. F. Newman, P. S. Marshall, H. Arlinghaus, M. R. Alexander, A. West, S. Horning, E. Niehuis, A. Makarov, C. T. Dollery, I. S. Gilmore, Nat. Methods 2017, 14, 1175.

[76] M. Aichler, A. Walch, Lab. Invest.: J. Tech. Methods Pathol. 2015, 95, 422.

[77] M. Holzlechner, K. Strasser, E. Zareva, L. Steinhauser, H. Birnleitner, A. Beer, M. Bergmann, R. Oehler, M. MarchettiDeschmann, J. Proteome Res. 2017, 16. 65.
[78] A. W. Kay, D. M. Strauss-Albee, C. A. Blish, Methods Mol. Biol. 2016, $1441,13$.

[79] H. Rodriguez, R. Rivers, C. Kinsinger, M. Mesri, T. Hiltke, A. Rahbar, E. Boja, Proteom. Clin. Appl. 2010, 4, 904.

[80] E. W. Deutsch, C. M. Overall, J. E. Van Eyk, M. S. Baker, Y. K. Paik, S. T. Weintraub, L. Lane, L. Martens, Y. Vandenbrouck, U. Kusebauch, W. S. Hancock, H. Hermjakob, R. Aebersold, R. L. Moritz, G. S. Omenn, J. Proteome Res. 2016, 15, 3961.

[81] D. M. Good, V. Thongboonkerd, J. Novak, J. L. Bascands, J. P. Schanstra, J. J. Coon, A. Dominiczak, H. Mischak, J. Proteome Res. 2007, 6, 4549.

[82] S. M. Ahn, R. J. Simpson, Proteom. Clin. Appl. 2007, 1, 1004.

[83] S. Hu, J. A. Loo, D. T. Wong, Proteomics 2006, 6, 6326.

[84] P. E. Geyer, L. M. Holdt, D. Teupser, M. Mann, Mol. Syst. Biol. 2017, 13, 942.

[85] Q. Wang, R. Chaerkady, J. Wu, H. J. Hwang, N. Papadopoulos, L. Kopelovich, A. Maitra, H. Matthaei, J. R. Eshleman, R. H. Hruban, K. W. Kinzler, A. Pandey, B. Vogelstein, Proc. Natl Acad. Sci. USA 2011, 108, 2444

[86] A. J. Percy, J. Yang, A. G. Chambers, J. S. Hill, G. V. Freue, C. H. Borchers, Proteomics 2012, 12, 1222.

[87] A. N. Hoofnagle, J. O. Becker, M. H. Wener, J. W. Heinecke, Clin. Chem. 2008, 54, 1796.

[88] T. A. Addona, X. Shi, H. Keshishian, D. R. Mani, M. Burgess, M. A. Gillette, K. R. Clauser, D. Shen, G. D. Lewis, L. A. Farrell, M. A. Fifer, M. S. Sabatine, R. E. Gerszten, S. A. Carr, Nat. Biotechnol. 2011, 29, 635.

[89] J. Albrethsen, H. Frederiksen, T. H. Johannsen, A. M. Andersson, A. Juul, Clin. Chim. Acta 2018, 477, 18.

[90] A. Banaei-Esfahani, C. Nicod, R. Aebersold, B. C. Collins, Curr. Opin. Microbiol. 2017, 39, 64.

[91] R. W. Sprung, M. A. Martinez, K. L. Carpenter, A. J. Ham, M. K. Washington, C. L. Arteaga, M. E. Sanders, D. C. Liebler, J. Proteome Res. 2012, 11, 3498.

[92] J. J. Kennedy, J. R. Whiteaker, R. M. Schoenherr, P. Yan, K. Allison, M. Shipley, M. Lerch, A. N. Hoofnagle, G. S. Baird, A. G. Paulovich, J. Proteome Res. 2016, 15, 2717.

[93] D. K. Bhatt, B. Prasad, Clin. Pharmacol. Ther. 2018, 103, 619.

[94] K. Nakamura, M. Hirayama-Kurogi, S. Ito, T. Kuno, T. Yoneyama, W. Obuchi, T. Terasaki, S. Ohtsuki, Proteomics 2016, 16, 2106.

[95] L. Litichevskiy, R. Peckner, J. G. Abelin, J. K. Asiedu, A. L. Creech, J. F. Davis, D. Davison, C. M. Dunning, J. D. Egertson, S. Egri, J. Gould, T. Ko, S. A. Johnson, D. L. Lahr, D. Lam, Z. Liu, N. J. Lyons, X. Lu, B. X. MacLean, A. E. Mungenast, A. Officer, T. E. Natoli, M. Papanastasiou, J. Patel, V. Sharma, C. Toder, A. A. Tubelli, J. Z. Young, S. A. Carr, T. R. Golub, A. Subramanian, M. J. MacCoss, L. H. Tsai, J. D. Jaffe, Cell Syst. 2018, 6, 424.

[96] M. A. Gillette, S. A. Carr, Nat. Methods 2013, 10, 28.

[97] P. Wu, Z.J. Heins, J.T. Muller, A.A. Abeshouse, Y. Sun, N. Schultz, D. Fenyo, J. Gao, bioRxiv 2018, https://doi.org/ 10.1101/247718.

[98] T. Muth, J. Peters, J. Blackburn, E. Rapp, L. Martens, J. Proteome 2013, 88, 104.

[99] B. D. Halligan, J. F. Geiger, A. K. Vallejos, A. S. Greene, S. N. Twigger, J. Proteome Res. 2009, 8, 3148.

[100] O. T. Schubert, H. L. Rost, B. C. Collins, G. Rosenberger, R. Aebersold, Nat. Protocols 2017, 12, 1289. 